\title{
Moving forward with the AENJ Strategic Plan
}

Welcome to Volume 12 Issue 1 . Our year begins with a renewed direction, a renewed purpose, and a fresh new look. In the last issue I heralded how the AENJ is responding to the many challenges in emergency nursing practice and moving forward with a new strategic plan. First, our vision for the Australasian Emergency Nursing Journal was crystallised in Ways Forward 1 - The AENJ 2015 Strategic Statement. The statement outlines our vision for the future, and will guide of efforts at all levels within the AENJ. It is the reference point from which we will measure our performance. Second, I announced a new structure for the AENJ Editorial Management Team in Ways Forward 2 - Building the Editorial Management Team. I called for expressions of interest for Deputy Editors and Associate Editors for the Australasian Emergency Nursing Journal. Third, I announced the establishment of a new International Editorial Board in Ways Forward 3 - Building the International Editorial Board (IEB). Interest in the positions of Deputy Editor (Clinical Practice and Professional Standards), Deputy Editor (Research and Scholarship) and the various Associate Editors (Specialty) have been strong. Formal appointments will be made and announced in the coming months. I am pleased to announce and welcome the following appointments of Expert Members to the AENJ International Editorial Board:

Professor Megan-Jane Johnstone, Australia

Professor Paul Arbon, Australia

Assistant Professor Wanpenpin Pinyopasakul, Thailand

Dr Katarina Göransson, Sweden

Associate Professor Paul Middleton, Australia

Ms Julie Finucane OAM, Australia

There will be many Expert Member appointments in the coming months drawing on our extensive panel of reviewers and other national and international experts.

I am also pleased to announce the first of our CENA Constitutional Member appointments:

Daniel Gordon, Australia (ACT)

Julie Considine, Australia (VIC)

Kate Curtis, Australia (NSW)
Appointment of the existing CENA Constitutional Members will be finalised in the coming months.

Building on this work, I present the next three strategic elements of the AENJ 2009-2013 Strategic Plan: for the Australasian Emergency Nursing Journal.

\section{Ways Forward 4: Rebadging the AENJ}

We have a new cover and masthead. These were developed following consultation with members of the AENJ Editorial Board and Editorial Management Team, and the CENA Board of Directors. In the future, the cover will include a photograph or illustration relevant to theme issues or key articles of interest.

\section{Ways Forward 5: International emergency nurse readership survey}

The AENJ will lead an international consortium of emergency nursing journals in the International Emergency Nurse Readership Study. The purpose of this study is to come to understand the needs of the readership of emergency nursing journals and what emergency nurses are reading to prepare them for contemporary practice. Using an electronic survey, the study will examine what kinds of literature and materials emergency nurses read and access in their professional practice. The survey will be conducted by the leading international emergency nursing journals: the Australasian Emergency Nursing Journal, the Journal of Emergency Nursing, Advanced Emergency Nursing Journal, and International Emergency Nursing. This study is a major achievement of the AENJ as we expand our presence in the international publishing arena.

\section{Ways Forward 6: Application for indexing in MEDLINE}

The next 12 months will see the AENJ turn its attention to indexing in MEDLINE. Achieving MEDLINE indexation is a critical element in building the quality of the AENJ 
in the international research and scholarship arena.

Ramon Shaban

Further details of this will be provided in the coming Editor-in-Chief issues.

I look forward to working with you in Building the AENJ, and our Ways Forward for the Future.

Australasian Emergency Nursing Journal, College of Emergency Nursing Australasia, Brisbane, Australia E-mail address: editor@cena.org.au 